A Critical Investigation and an Application of the Rat Growth Method for the Study of Vitamin B.

\author{
$3 Y$ \\ ADELAIDE SPOHN
}

Submitted in Partial Fulfillment of the Requirements for the Degree of Doctor of Philosophy in the Faculty of Pure Science,

Columbia University. 


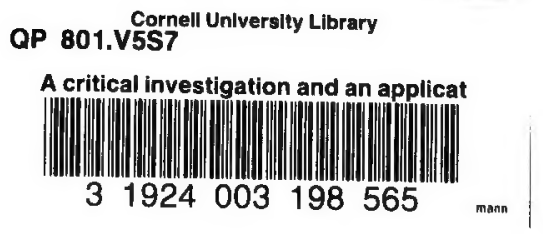




\title{
A Critical Investigation and an Application of the Rat Growth Method for the Study of Vitamin B.
}

\author{
BY \\ ADEL.AIDE SPOHN
}

Submitted in Partial Fulfillment of the Requirements for the Degree of Doctor of Philosophy in the Faculty of Pure Science, Columbia University.

NEW YORK

1922

cs 


\section{ACKNOWLEDGMENTS}

This investigation was undertaken at the suggestion of Professor H. C. Sherman and carried out tunder his direction. The author wishes to express to Professor Sherman her appreciation for advice and encouragement received during the course of the work.

The author wishes also to express thanks to Professor A. W. Thomas for helpful suggestions. 


\section{CONTENTS}

I. Introduction.

II. Experimental Procedure.

1. Selection and Care of Animals.

2. Basal Ration and its Preparation.

3. Source of Vitamin B, Treatment and Manner in Which it Was Fed.

III. The Adequacy of the Basal Diet.

IV. Determination of the most Advantageous Dose for Measuring Heat Destruction of Vitamin B in Skimmed Milk Powder.

1. Feeding the Milk Separately from the Rest of the Diet.

2. Feeding the Dried Milk Mixed with the Rest of the Diet.

V. The Effect of Heat upon Vitamin B in Milk in the Dry and Fluid State.

1. Experiments with Reconstructed Milk Fed Separately from the Rest of the Diet.

2. Experiments with Milk Mixed with the Rest of the Diet.

VI. Summary. 



\section{A CRITICAL INVESTIGATION AND AN APPLICATION OF THE RAT GROWTH METHOD FOR THE STUDY OF VITAMIN B.}

\section{INTRODUCTION}

The term "vitamin B" is here used synonomously with "water soluble B" as a designation for the water soluble growth promoting substance whose existence as an essential constituent of the food was demonstrated by Hopkins ${ }^{1}$ \& 2, Osborne and Mendel ${ }^{3-7}$, and McCollum and Davis ${ }^{8-11}$ by growth experiments with young mammals, chiefly rats. Whether this is identical with the antineuritic substance studied by Eijkman ${ }^{12.14}$, Funk ${ }^{15-16}$, Williams ${ }^{17-20}$ and others through experiments with birds, or with the "bios" of Wildiers ${ }^{21}$. which shows a growth promoting property toward yeast, does not concern the present investigation. 'The recent publication of a monograph The Vitamins by the American Chemical Society ${ }^{22}$ makes it unnecessary to review previous work at length in this connection.

The importance of vitamin $B$ as a factor in food values makes desirable the standardization of the method of studying this substance so as to permit of quantitative investigation of the relative amounts in different foods or in the same food before and after heating or other treatment to which foods may be subjected in the course of preservation or cooking.

When such methods are sufficiently developed they can also be applied to the quantitative measurement of the concentration of the vitamin at successive steps in attempts to isolate the substance from natural sources and bring it to a condition of maximum purity for the determination of its chemical nature.

For the present investigation white rats were selected as the experimental animal and dried skimmed milk as the vitamin-containing food. Examination of the literature, as well 
as the author's experience, shows that the pigeon method for studying the vitamin $B$ content of food, by the power of the substance to prevent or cure polyneuritis, yields rather irregular results ${ }^{15}, 22,36,38$. The method of testing for vitamin $B$ by measuring the acceleration of yeast growth is open to the question whether the culture medium is adequate in all other respects and whether it is safe to assume that increased yeast is attributable entirely to the vitamin ${ }^{23-85}$. The nutrition requirements and rate of growth of the rat have been extensively studied by Hopkins ${ }^{1,2,36}$, Osborne and Mendel ${ }^{3-7}$, McCollum ${ }^{8-11}$ and others. The rat method is therefore the best standardized by previous work. Dr. Harriet Edgeworth ${ }^{37}$, working in this laboratory, after a careful analysis of the yeast and rat growth methods concluded: "The rat growth method involves somewhat larger probable errors than the yeast method, but can be interpreted in terms of B vitamin with much greater certainty and is therefore the preferable method." Skimmed milk in the form of dry powder was chosen as the source of vitamin B, since it furnishes the vitamin in a typical natural state, readily available and uniform. It is easily and accurately manipulated in either large or small quantities and is convenient for study in either the fluid or dry state.

\section{EXPERIMENTAL PROCEDURE}

Selection and Care of Animals. The rats used were twentyeight or twenty-nine days old, this being the time of weaning adopted in this laboratory, and weighed from thirty to sixtyfive grams when placed on the experimental diet. The experimental animals all came from mothers on a diet of two-thirds whole wheat, one-third whole milk and sodium chloride, two per cent. of the weight of the wheat (diet 13) or this diet with an addition of ten grams of raw lean beef per adult rat per day (diet $13 \mathrm{M}$ ). In each experiment, however, care was taken, that equal numbers of comparison and control rats came from mothers on the same diet. The lots were made up in the following manner. If, for example, in one experiment 
there were five variations of the diet and ten rats for each variation, then fifty rats were required. Six to eight litters of from five to ten animals each would be needed to supply this number of rats. Each litter was distributed over the five variations as far as it would go. For example, a litter of nine rats would furnish two animals each for four variations and one for the fifth. Then a litter of six rats would provide for one rat where there were two before, and two rats where there was one before, making a total of three rats for each variation of the diet. The remaining thirty-five rats from the various litters were portioned out so that there were ten animals in each lot, and in such a way that the total weight of the rats and the number of males and females on each modification was practically the same.

The experiments were continued for eight weeks, from the begining of the fifth to the end of the twelfth week of the rat's life, this being the most rapid growth period. A number of experiments were continued for four weeks longer. These last four weeks, however, did not show any significant differences which were not brought out in the growth curves from the fourth through the twelfth week.

When the milk, which was the source of vitamin B, was fed separately from the rest of the diet, the animals were kept in round galvanized iron wire cages, eight inches high and nine inches in diameter, one rat in each cage. In addition to the milk these rats received a vitamin $B$-free basal ration, of which they ate ad libitum. In the experiments in which the rats received the milk mixed with the rest of the diet, which was always before them, six to eight animals were housed in square iron wire cages $11^{\prime \prime} \times 14^{\prime \prime} \times 10^{\prime}$. Fresh water was always available. The cages were cleaned as often as seemea necessary, the large cages usually every day and the small round cages three times a week. Each animal was weighed once a week and the food remaining weighed and subtracted from the amount fed, the difference being the amount consumed by the rat or rats during that week.

Basal Ration and its Preparation. The basal ration used was planned to contain all the essential food factors in optimum 
amounts, with the exception of vitamin B which was lacking. It had the following composition:

\section{Diet 94}

Casein per cent.

Butter fat

18

Starch

Salt mixture (Osborne and Mendel) ${ }^{40}$

4

Later, merely as a factor of safety, cod liver oil was substituted for one-fifth of the butter fat, making diet 107. The ingredients of the diet were weighed out and intimately mixed first by hand and then transferred to a mechanical mixer and stirred for five minutes.

The casein was prepared from the commercial product by purification in the manner suggested by Sherman and Husa (unpublished experiments) as follows: One liter of 60 per cent. alcohol (by weight) was added to 200 grams of casein and the mixture stirred for one-half hour by means of a mechanical stirrer and was then allowed to stand for five and one-half hours. After this period the casein was filtered off through a Buchner funnel and washed once in the funnel with $500 \mathrm{cc}$. of 60 per cent. alcohol. The casein was again treated with one liter of 60 per cent. alcohol as before but this time was left to stand for eighteen hours. It was filtered off and washed as before with $500 \mathrm{cc}$. of 60 per cent. alcohol and finally with $500 \mathrm{cc}$. of 90 per cent. alcohol. The last washing merely facilitates the drying. The casein was removed from the filter and spread out in a thin layer and allowed to become air-dry. Throughout this paper the strength of alcohol used is always given in per cent. by weight.

The butter was melted at a temperature not exceeding $45^{\circ}$ C. All the curd, salt and water settles to the bottom of the vessel and may be easily removed when the butter solidifies. The butter fat is again melted at a low temperature, and filtered through filter paper using a hot water funnel.

The salt mixture described by Osborne and Mendel ${ }^{40}$ was used. Commercially pure corn starch, which according 
to these authors contains no appreciable quantities of the water soluble vitamin furnished the carbohydrate of the $\operatorname{diet}{ }^{39}$.

Source of Vitamin B, Treatment and Manner in Which it Was Fed. Dried skimmed milk was used as a convenient source of vitamin B. It permits the study of the effect of heat on the vitamin both in the wet and dry state. By using skimmed milk powder from the same lot throughout one experiment, possible variation in vitamin content is eliminated.

The dry milk was heated at $100^{\circ} \mathrm{C}$. for six, twenty-four and forty-eight hours in a constant temperature oven. It was spread out in thin layers about one-half inch in thickness and the temperature taken by means of a thermometer extending into the dry milk. Two hours were allowed, which was the time found to be necessary for the milk to come to $100^{\circ} \mathrm{C}$. The portions heated six, twenty-four and forty-eight hours respectively actually remained in the oven eight, twenty-six and fifty hours.

The reconstructed milk was prepared by weighing out 100 grams of the air-dry powder and making it up to $1,000 \mathrm{cc}$. with water. For the heat treatment $250 \mathrm{cc}$. of this was poured into an Erlenmeyer flask and tightly stoppered with cotton. This was heated in a vigorously boiling water bath for six hours. A thermometer extending into the milk actually recorded a temperature of $99.5^{\circ} \mathrm{C}$. to $99.8^{\circ} \mathrm{C}$. At the end of six hours the flask was removed from the bath and rapidly cooled under the tap. Since the volume diminished, due to evaporation through the stopper, the milk was again made up to volume before using.

The milk was fed in doses of 8 cc. per rat per day for seven days a week, this; as will later be shown, being the amount which would best reveal any variation in vitamin content. The milk was measured into a small cup by means of a graduated pipette and placed into the cage each day. If the rat did not drink the milk readily, the water cup was removed for the day and replaced in the evening. Usually this treatment brought the desired results. After two to three days all the rats took all the milk that was given them. The milk 
heated dry was fed in two ways: (1) mixed with the rest of the diet, replacing 25 per cent. of the starch in diet 94 . This ration was always available and the rats ate ad libitum. (2) In another series of experiments the milk, which was heated dry, was reconstructed before feeding by making 25 grams up to a volume of $250 \mathrm{cc}$. with water. This was fed in doses of $8 \mathrm{cc}$. per rat per day. The advantage here is that all the rats received exactly the same amount of vitamin per day. Positive controls, animals receiving in the one case the diet containing 25 per cent. of unheated milk and in the other case $8 \mathrm{cc}$. per day of the reconstructed unheated milk, were run in every case in comparison with the rats receiving the heated food. Negative controls, receiving only the vitamin-free diet were run in almost all but not every experiment. This was done in order to make sure that the basal diet did not vary.

\section{THE ADEQUACY OF THE BASAL DIET}

In order to prove that the basal ration contained the optimum amounts of the various constituents, it was fed to a series of rats in comparison with diets in which each ingredient of the basal ration, the casein, butter fat and salt mixture, were in turn used in larger amounts. It was thought that perhaps another protein such as extracted meat might prove to be a more adequate protein, or the meat might be more palatable and that therefore the rats would eat more of the basal ration. Consequently diet 94 was also compared with a diet in which extracted meat residue replaced the casein. Commercial extracted meat residue was purified according to the method described for casein (page 7).

TABLE, I.

The following diets were used in the comparison:

\begin{tabular}{|c|c|c|c|c|c|}
\hline \multirow[t]{2}{*}{ Diet } & 94 & 102 & 103 & 105 & 104 \\
\hline & $\%$ & $\%$ & $\%$ & $\%$ & $\%$ \\
\hline Casein & 18 & 18 & 23 & 18 & $18^{*}$ \\
\hline Butter fat $\ldots \ldots \ldots \ldots \ldots$ & 10 & 15 & 10 & 10 & 10 \\
\hline Starch $\ldots \ldots \ldots \ldots \ldots$ & 68 & 63 & 63 & 67 & 68 \\
\hline Salt mixture $(\mathrm{O} . \& \mathrm{M} .)^{40} \ldots$ & 4 & 4 & 4 & 5 & 4 \\
\hline
\end{tabular}

* Meat residue. 
The average growth curves on these various diets were practically identical and the average duration of life varied by only four days. Table II briefly summarizes the results of this series of experiments.

\section{TABLE II.}

Summary of average results on diets 94, 102, 103, 104, 105.

\begin{tabular}{|c|c|c|c|c|}
\hline Diet & $\begin{array}{l}\text { of } \\
\text { rats }\end{array}$ & $\begin{array}{l}\text { initial } \\
\text { weight }\end{array}$ & $\begin{array}{l}\text { weight } \\
\text { at death }\end{array}$ & $\begin{array}{l}\text { age at } \\
\text { death }\end{array}$ \\
\hline & 12 & 47 gms. & 34 gms. & 61 days \\
\hline 102. & 8 & $46 "$ & 31 & 65 \\
\hline 103. & 8 & 47 " & 34 " & 64 \\
\hline 105. & 8 & 47 " & 34 " & 63 \\
\hline & 8 & 46 “ & 33 “ & 62 \\
\hline
\end{tabular}

It was thought that the results might be different if vitamin $B$ were added to the diets, in other words if this vitamin was not the limiting factor in the diet. At about this time in the course of the work, it was also thought wise, merely as a factor of safety, to replace 2 per cent. of the butter fat in the diet by cod liver oil. Each rat in this comparison received either diet 107, 108, 109, or 110 with an addition of $7 \mathrm{cc}$. or $8 \mathrm{cc}$. of reconstructed skimmed milk. 'These doses were used, since from experiments reported later in the paper it became apparent that one or the other of these amounts would probably give the best results in the study of the destruction of water-soluble $\mathrm{B}$ by heat. $8 \mathrm{cc}$. was later decided upon as the best dose but the results for both are here given, both being valuable in this connection.

\section{TABLE III.}

The following diets were used in the second comparison:

Diet 107 108 109 110

$\%$

Casein ............... 18

$\%$

$\%$

Butter fat $\ldots \ldots \ldots \ldots \ldots \ldots, 8$

18

Cod liver oil ............ 2

13

8

Starch ................ 68

2

2

Salt mixture (O. \& M.) ${ }^{40} \ldots$. 4

63

63 
Table IV gives a summary of the results of the comparison of diet 107 with diet 108 containing 5 per cent. more butter fat, diet 109 containing 5 per cent. more casein and diet 110 with an excess of 1 per cent. salt mixture over that in diet 107.

TABLE IV.

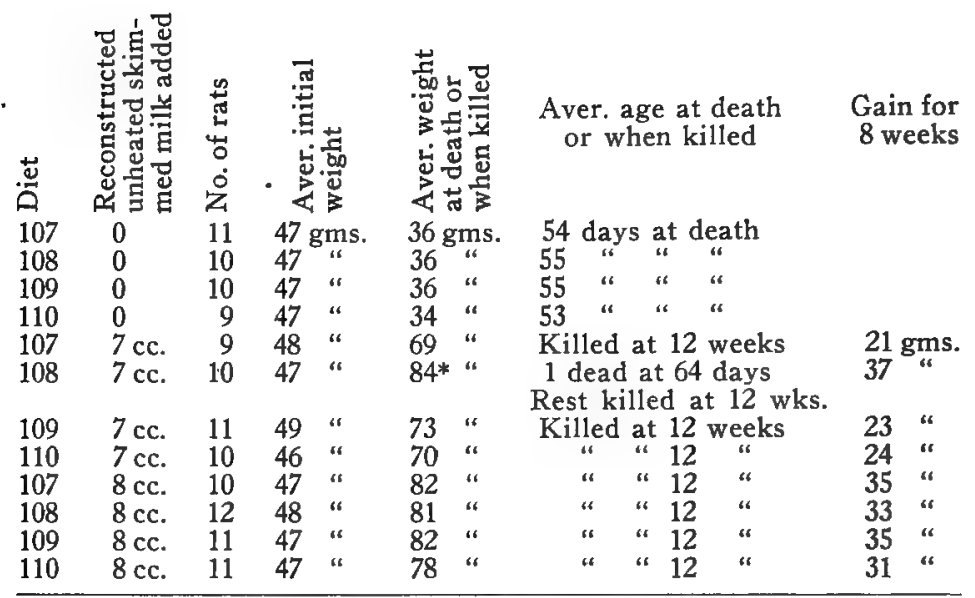

* 84 gms, is the average weight of 9 rats at 12 weeks of age.

The results of the experiments tabulated in Table IV are the same as those in the previous series (Table II). It appears from the data that the basal rations 94 and 107 furnish optimum amounts of the essential food factors, protein, fat, mineral salts and vitamin $\mathrm{A}$.

\section{DETERMINATION OF THE MOST ADVANTAGEOUS DOSE FOR MEASURING HEAT DESTRUCTION OF VITAMIN B IN SKIMMED MILK POWDER.}

Feeding the Milk Separately from the Rest of the Diet. It was next necessary to determine the amount of milk to feed in order to detect most readily any change in the water soluble $\mathrm{B}$ content upon heating the milk. Increasing amounts of milk were superimposed on the basal diet and a study made of the growth curves in relation to size of the dose. The milk was 
fed in doses of 2 cc., 4 cc., 6 cc., 8 cc., 10 cc., 12 cc., 15 cc., per rat per day. These amounts were fed without regard to the weight of the rat and the same amount was fed throughout the experimental period. The data are summarized in Tables $\mathrm{V}$ and VI and Chart I, Figures I and II.

\section{TABLE V.}

Diet 94 and unheated milk.

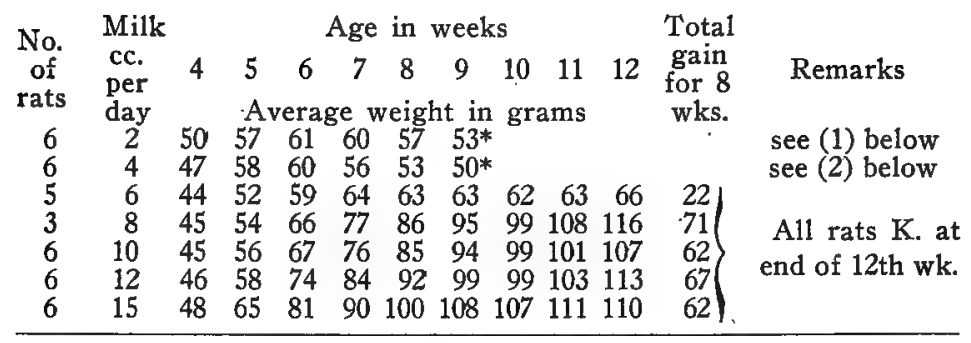

$\mathrm{K} .=$ killed.

$$
\mathrm{D} .=\text { dead. }
$$

* Since all rats did not live till the end of the experimental period, averages could not be given for the last three weeks.

(1) 4 rats $D$. at $64,65,77,77$ days.

2 rats $\mathrm{K}$. at end of 12 th wk.

(2) 4 rats $D$. at $63,66,70,74$ days.

2 rats $K$. at end of 12 th wk.

\section{TABLE VI.}

Diet 107 and unheated milk.

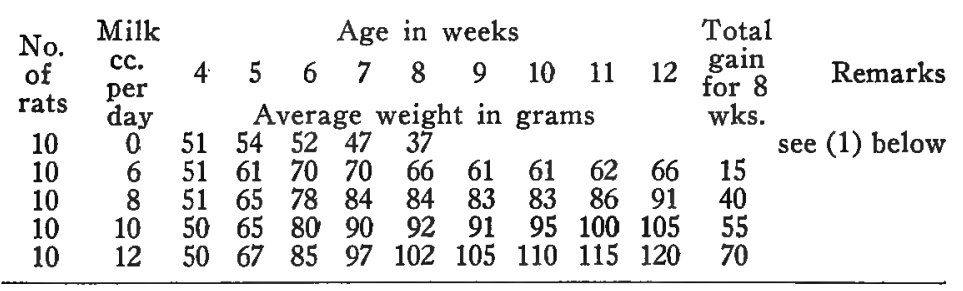

(1) 37 gms.=average weight at death.

56 days=average age at death.

It will be noted that in both experiments (Tables V and VI) the largest difference in weight gained for the same difference in milk fed comes between $6 \mathrm{cc}$. and $8 \mathrm{cc}$. In order to prove 
conclusively that the $8 \mathrm{cc}$. dose is the best one to use, three lots of six rats each were given diet 94 with the addition of $6 \mathrm{cc}$., $7 \mathrm{cc}$., and $8 \mathrm{cc}$. of skimmed milk respectively per rat per day. The animals receiving $6 \mathrm{cc}$. of the milk gained an average of 34 grams in eight weeks, those receiving $7 \mathrm{cc}$. averaged 35 grams gain and the rats fed $8 \mathrm{cc}$. averaged 56 grams.

Eight cc. of skimmed milk per rat per day is probably the best level at which to feed in order to detect any change in the vitamin $B$ content of the milk, since it is at this level that we get the largest difference in the total gain in weight for eight weeks, as compared with the next lower amount fed. This does not furnish the optimum amount of vitamin $B$, since further addition of milk gave increased growth in many cases and in the general average.

In another experiment the amount of milk given was varied in accordance with the weight of the rat. Each animal received $0.05,0.075,0.10$ or 0.125 grams of skimmed milk powder $(0.50,0.75,1.00$ or $1.25 \mathrm{cc}$. reconstructed milk) per 10 grams of rat per day. The amount of milk fed was calculated on the basis of the weekly weighings, the milk fed each day for a week being determined from the weight of the rat at the beginning of the week. It was expected that this method would yield more consistent results and that the variation among individuals receiving the same amount of vitamin $B$ would be lessened by this method of feeding. The results, however, do not bear out this assumption. A comparison of the weight curves of the individual rats which were fed the same amount of milk throughout the experimental period regardless of body weight, with those of the rats receiving the graduated doses, shows that the former are as uniform as those in the other series. Table VII summarizes the results of the experiments in which the rats received the graduated doses. 0.1 gram of milk per day per 10 grams of rat is apparently the best level at which to feed the milk by this method, since for the same difference in amount of milk given a greater difference in weight gained is observed between this and the next lower amount, than between any other two successive doses. The method was not adopted since it gave no 
assurance of having any advantage over the former, and the former was easier of application.

\section{TABLE VII.}

Diet 94 and unheated skimmed milk fed in fluid state.

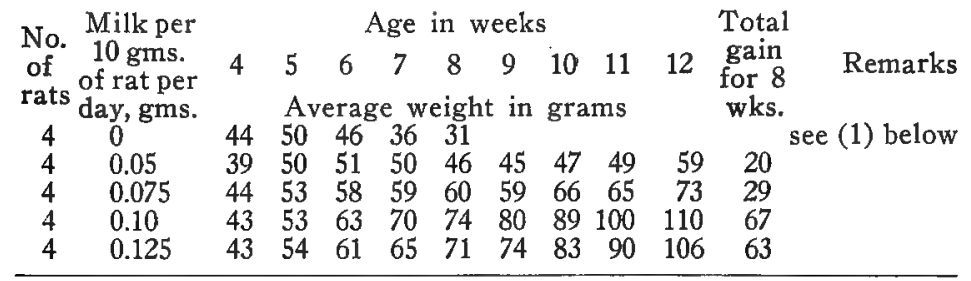

(1) 31 gms.=average weight at death.

55 days=average age at death.

Feeding the Dried Milk Mixed With the Rest of the Diet. For the experiments in which the dried milk was mixed with the rest of the diet, it was essential to determine the proportion in which the milk should be added in order to make the test for possible differences in vitamin B content, most delicate. The starch in diet 94 was replaced by skimmed milk in amounts varying from 2.5 per cent. to 30.0 per cent. The diets are given in Table VIII.

\section{TABLE VIII.}

Diet $\ldots \ldots \ldots \ldots \ldots \ldots .94 \quad 98 \quad 97 \quad 96 \quad 95 \quad 99100101$

$\begin{array}{rrrrrrrr}\% & \% & \% & \% & \% & \% & \% & \%\end{array}$

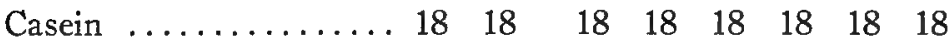

$\begin{array}{lllllllll}\text { Butter fat ............ } 10 & 10 & 10 & 10 & 10 & 10 & 10 & 10\end{array}$

Salt mixture (O. \& M.) $)^{40} \quad 4 \quad 4 \quad \begin{array}{lllllll}4 & 4 & 4 & 4 & 4 & 4\end{array}$

$\begin{array}{llllllllll}\text { Skimmed milk powder... } & 0 & 2.5 & 5 & 10 & 15 & 20 & 25 & 30\end{array}$

$\begin{array}{lllllllllll}\text { Starch } \ldots \ldots \ldots \ldots \ldots & 68 & 65.5 & 63 & 58 & 53 & 48 & 43 & 38\end{array}$

The rats used in these experiments came either from mothers on Diet 13 or $13 \mathrm{M}$. The data for the animals from the two sources have been summarized separately and are given in Tables IX and $\mathrm{X}$ and the combined results in Table XI. See also Chart II, Figure I. 


\section{TABLE IX.}

Rats from mothers on Diet 13 .

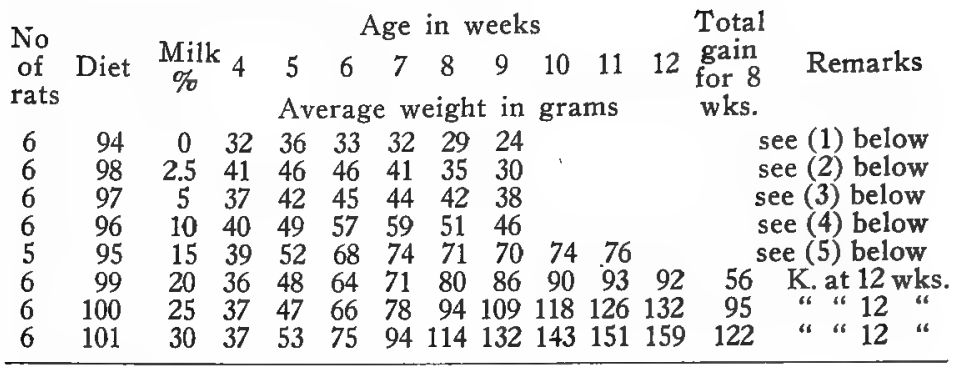

$\mathrm{K} .=$ killed.

D. $=$ died.

(1) $24 \mathrm{gms}$ =average weight at death

*69 days=average age at death.

(2) 30 gms = =average weight at death.

65 days =average age at death.

(3) 4 rats D. at $53,63,68,69$ days.

2 rats $K$. at 12 weeks.

(4) 2 rats $D$, at 61,65 days.

4 rats $K$. at 12 weeks.

(5) 1 rat $D$. at 11 weeks.

4 rats $K$. at 12 weeks.

* The average age at death here is high, due to the fact that one rat lived 100 days.

\section{TABLE X.}

Rats from mothers on diet $13 \mathrm{M}$.

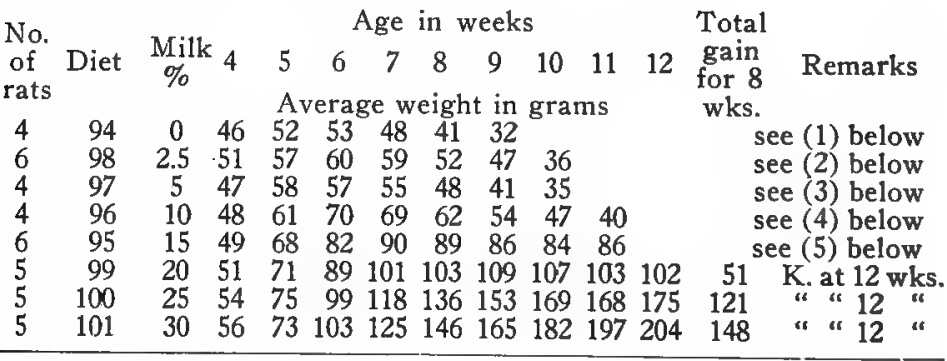

$\mathrm{K} .=$ killed.

D. = died.

(1) 32 gms.=average weight at death.

62 days=average age at death.

(2) 36 gms.=average weight at death.

71 days=average age at death.

(3) 35 gms.=average weight at death.

71 days=average age at death.

(4) $40 \mathrm{gms}$.=average weight at death.

75 days=average age at death.

(5) 2 rats $D$. at 74 days.

4 rats $K$. at 12 weeks. 


\section{TABLE XI.}

(Combined results of Tables IX and X.)

Rats from mothers on Diet 13 and $13 \mathrm{M}$.

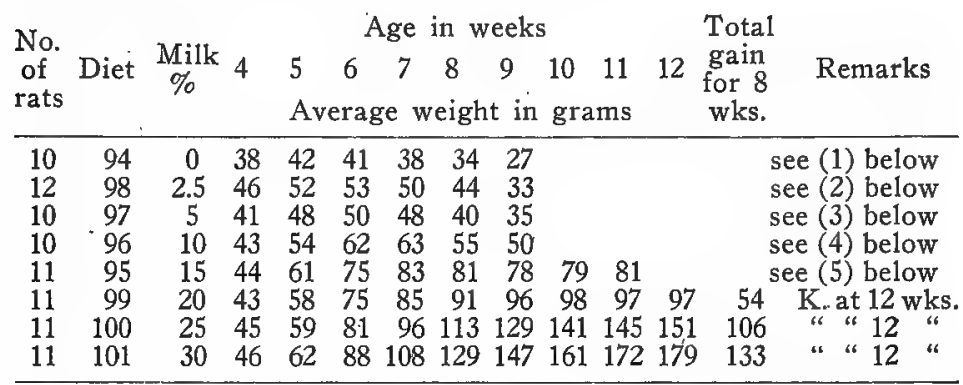

$\mathrm{K} .=$ killed.

D. $=$ died.

(1) $27 \mathrm{gms}=$ =average weight at death. 66 days=average age at death.

(2) 33 gms.=average weight at death. 68 days=average age at death.

(3) 8 rats D. in $69,68,63,53,75,73,69,67$ days. 2 rats $\mathrm{K}$. at 12 weeks.

(4) 6 rats D. at $65,61,75,82,72,72$ days. 4 rats $K$. at 12 weeks.

(5) 3 rats $D$. at $74,74,77$ days. 8 rats $K$. at 12 weeks.

The greatest difference in rate of growth for a difference of 5 per cent. in the amount of milk contained in the diet, is found between 20 and 25 per cent. Obviously then the ration containing 25 per cent. of skimmed milk powder is the proper one to use in a study of the change in the water soluble $B$ content of skimmed milk powder upon heating.

A study of Tables IX and X further shows a decided difference between the animals from the two sources. Rats from mothers on Diet $13 \mathrm{M}$ grew faster and maintained a higher average weight than the animals from mothers on Diet 13 alone. The young rats from Diet $13 \mathrm{M}$ are evidently more vigorous and therefore make better growth. The data shows that it is essential either to use rats coming from mothers on the same diet or to take the same number of rats from each diet in making up matched lots of rats for comparison.

A typical experiment will suffice to show the variation among the individual animals on the same diet. The average 
figures for $8 \mathrm{cc}$. milk in Table VI were calculated from the data given in Table XII. .

\section{TABLE XII.}

Weights of 10 rats receiving Diet 107 and $8 \mathrm{cc}$. milk.

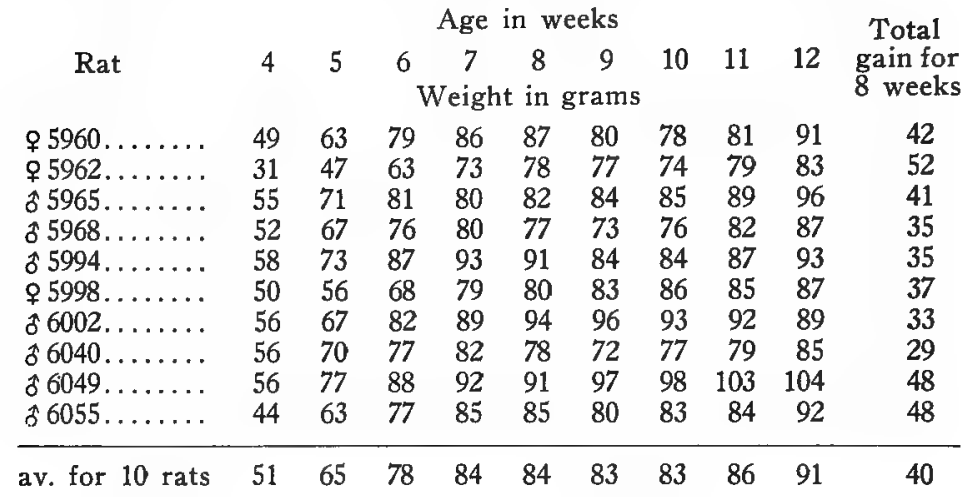

\section{THE EFFECT OF HEAT UPON VITAMIN B IN MILK IN THE DRY AND FLUID STATE.}

Experiments with Reconstructed Skimmed Milk Fed Separately from the Rest of the Diet. The skimmed milk powder used in this work was heated both dry and in the natural fluid state, in the manner described earlier in this paper. The liquid milk was heated for six hours at $100^{\circ} \mathrm{C}$. in a boiling water bath and the dry milk for 6,24 and 48 hours at $100^{\circ} \mathrm{C}$. in a constant temperature oven. In the experiments summarized in Table XIII each rat received $8 \mathrm{cc}$. of the reconstructed milk per day in addition to the basal ration $107,8 \mathrm{cc}$, as has been previously shown, being the dose which would be most likely to reveal any modification in the $B$ content of the milk. When the milk was heated dry it was mixed with water $(1 \mathrm{gm}$. milk in $10 \mathrm{cc}$. water) before feeding. The advantage of this method of feeding is that each animal receives exactly the same amount of the vitamin-containing food whereas in the experiments in which the milk is mixed with the rest of the food, the amount of vitamin the rat gets depends upon how much food it eats. 


\section{TABLE XIII.}

Diet 107 and $8 \mathrm{cc}$. of milk treated in various ways.

\begin{tabular}{|c|c|c|c|c|c|c|c|c|c|c|c|}
\hline \multirow{3}{*}{$\begin{array}{l}\text { No. of } \\
\text { rats }\end{array}$} & \multirow{3}{*}{$\begin{array}{l}\text { Milk } \\
\text { treatment }\end{array}$} & \multicolumn{8}{|c|}{ Age in weeks } & \multirow{2}{*}{\multicolumn{2}{|c|}{$\begin{array}{l}\text { 'lotal } \\
\text { gain for }\end{array}$}} \\
\hline & & 4 & 5 & 6 & 7 & 8 & 9 & 10 & 11 & & \\
\hline & & \multicolumn{8}{|c|}{ Average weight in grams } & & \\
\hline \multirow{5}{*}{$\begin{array}{l}10 \\
10 \\
10 \\
10 \\
10\end{array}$} & Unhe & 53 & 70 & 80 & 82 & 86 & 86 & 88 & 91 & 95 & 42 \\
\hline & Heated dr & 54 & 69 & 80 & 8 & 87 & 88 & 89 & 91 & & \\
\hline & Heated dry 2 & 54 & 68 & 76 & 7 & 79 & $7 \%$ & 78 & 7 & & \\
\hline & Heated dry 48 hrs. & 53 & 67 & 75 & 78 & 82 & 85 & 85 & 86 & 90 & 37 \\
\hline & st & 54 & 66 & 71 & 67 & 63 & 60 & 57 & 57 & 60 & 6 \\
\hline
\end{tabular}

The results in Table XIV are those of an experiment similar to the one just described, but in place of $8 \mathrm{cc}$, each rat received only $7 \mathrm{cc}$. of milk, this series of experiments having been completed before it was decided that $8 \mathrm{cc}$. would be the most satisfactory amount. In both experiments all the rats came from mothers on Diet $13 \mathrm{M}$.

\section{TABLE XIV.}

Diet 94 and $7 \mathrm{cc}$. of milk treated in various ways.

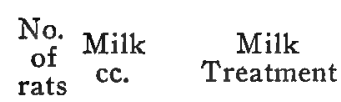

$\begin{array}{lll}3 & 0 & \\ 3 & 7 & \text { Unheated }\end{array}$

47 Heated dry 6 hrs.

47 Heated dry 24 hrs.

4. 7 Heated dry 48 hrs.

47 Heated in fluid state $6 \mathrm{hrs}$.
Age in weeks

\begin{tabular}{llllllllll}
4 & 5 & 6 & 7 & 8 & 9 & 10 & 11 & 12 & $\begin{array}{c}\text { Total } \\
\text { gain for }\end{array}$ \\
\hline
\end{tabular} Average weight in grams 8 weeks

$\begin{array}{llllll}42 & 43 & 44 & 38 & 32 & 1\end{array}$

$\begin{array}{llllllllll}45 & 59 & 70 & 71 & 71 & 68 & 64 & 64 & 64 & 19\end{array}$

$\begin{array}{llllllllll}45 & 57 & 72 & 78 & 74 & 71 & 67 & 64 & 62 & 17\end{array}$

$\begin{array}{llllllllll}46 & 59 & 75 & 78 & 74 & 71 & 67 & 63 & 59 & 13\end{array}$

$\begin{array}{llllllllll}40 & 50 & 61 & 66 & 69 & 68 & 64 & 57 & 57 & 17\end{array}$

$\begin{array}{llllll}40 & 61 & 68 & 65 & 59 & 53^{2}\end{array}$

132 grams = average weight at death, the average age being 53 days.

$\approx 53$ grams $=$ average weight at death, the average age being 62 days.

There is apparently a measurable destruction of vitamin $B$ when the milk is heated at $100^{\circ}$ for 6 hours in the fluid state. The average growth curve for the ten rats receiving $8 \mathrm{cc}$. of the reconstructed milk heated six hours at $100^{\circ} \mathrm{C}$. corresponds very closely to the average curve of the rats receiving $6 \mathrm{cc}$. of unheated milk (Tables V and VI). This indicates that approximately one-fourth of the total $B$ in the milk was destroyed when the fluid milk was heated for six hours at $100^{\circ} \mathrm{C}$. 
The seasonal differences in the growth of the rats ${ }^{1,2,42}$ and the possible seasonal variation in the vitamin content of the milk ${ }^{\perp}, 2,41,42,43,44$ are eliminated here, since the experiments (Tables $V$ and VI) were carried on at the same time in the early spring, late winter milk from the same lot being used in both series. The four rats receiving $7 \mathrm{cc}$. of reconstructed milk which had been heated, died at the ages of 50,60,66 and 66 days respectively, while the rats getting the same amount of unheated milk lived till the end of the twelfth week when they were killed. This is additional evidence of the destruction of vitamin $B$ by this heat treatment.

Dry heat applied for 6, 24 and 48 hours seems to have little or no deleterious effect, as the weight curves of the control rats receiving unheated milk and of those receiving the heated milk are approximately the same.

Experiments with Milk Mixed with the Rest of the Diet. Preliminary experiments reported elsewhere in this paper indicate that a change in the vitamin $\mathrm{B}$ content of skimmed milk powder may be most easily observed if the milk is mixed with the rest of the diet in the proportion equal to 25 per cent. of the entire mixture. Therefore the unheated milk of Diet 100 was replaced by the milk heated dry for various periods, 6, 24 and 48 hours. The animals from mothers on Diet $13 \mathrm{M}$ and Diet 13 placed on these diets have been summarized separately in Tables XV and XVI and the combined results are given in Table XVII and Chart II, Figure II. It will be noted here again, as was observed from the results of the experiments in which different amounts of milk replaced the starch in Diet 94 (Tables IX and X) that the rate of growth of the animals from Diet $13 \mathrm{M}$ is greater than that of the animals from Diet 13.

The total food consumed by the animals on Diet 100 and the diets in which the unheated milk of this ration was replaced by the milk heated 6,24 and 48 hours was practically the same in each case. The rats therefore received essentially the same number of calories and equal amounts of protein, of the mineral elements and of the vitamin containing food on the four different diets. 
TABLE XV.

Rats from mothers on Diet 13.

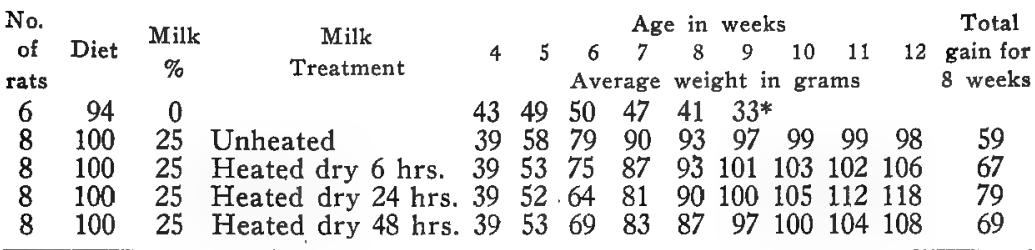

*33 gms.=average weight at death, the average age at death being 60 days.

TABLE XVI.

Rats from mothers on Diet $13 \mathrm{M}$.

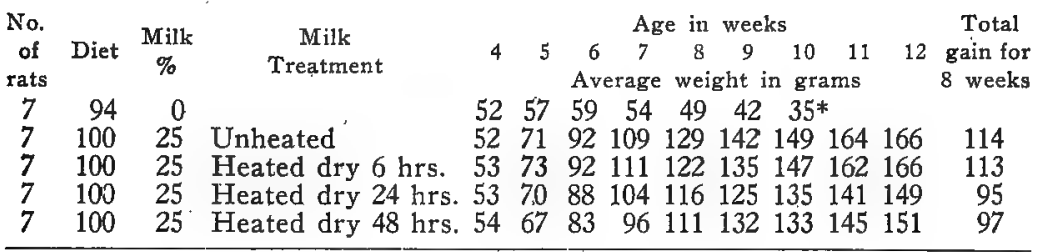

* 35 gms.=average weight at death, the average age being 67 days.

TABLE XVII.

(Results of Tables XV and XVI combined.)

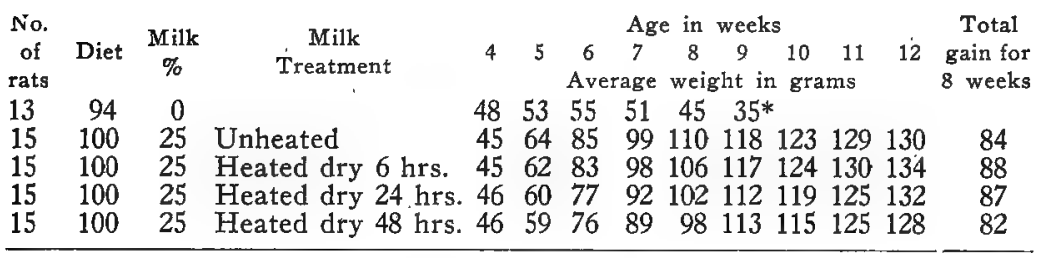

* 35 gms.=average weight at death, 64 days being the average age.

The conclusions to be drawn from these regarding the heat destruction of vitamin $B$ in the dry state, confirm those of the previous experiment in which the heated milk was fed separately. The average gain in weight for eight weeks on a control diet containing unheated milk and on the diets containing the milk heated for 6,24 and 48 hours is the same. There is evidently no destruction of the vitamin by this treatment or the amount of destruction is too small to be detected by either of the methods employed in the present work. 


\section{SUMMARY}

A quantitative method for the determination of relative amounts of vitamin $B$ is described. The work comprises eleven comparative studies with a total of thirty-eight variations of the basal diet and includes over six hundred quantitative studies of the growth of young rats.

An adequate basal ration is described which contains optimum amounts of all the food factors necessary for the growth of young rats with the exception of vitamin B.

The most advantageous quantities of milk to feed in order to detect possible differences in the vitamin $\mathrm{B}$ content were $8 \mathrm{cc}$. of skimmed milk or 0.8 gram of skimmed milk powder per rat per day when the milk was fed separately from the rest of the diet; or 25 per cent. of the total food mixture when the skimmed milk powder was mixed with the basal ration.

Feeding the basal ration under the conditions described to experimental animals of suitable age and size and sufficiently known dietary history, it is believed to be possible to detect a variation certainly of 25 per cent. and probably of 15 per cent. in the vitamin B content of the food tested.

There was no evidence of destruction of vitamin B in milk powder heated dry at $100^{\circ} \mathrm{C}$. even when this heating was continued for forty-eight hours. When the milk was heated in the fluid state for six hours at $100^{\circ} \mathrm{C}$. there was appreciable destruction of vitamin B. Apparently about one-fourth of the vitamin was destroyed. Vitamin $B$ is therefore very stable to heating at $100^{\circ} \mathrm{C}$. in the dry state, but somewhat less stable when heated at the same temperature in water solution. 


\section{CHART I.}

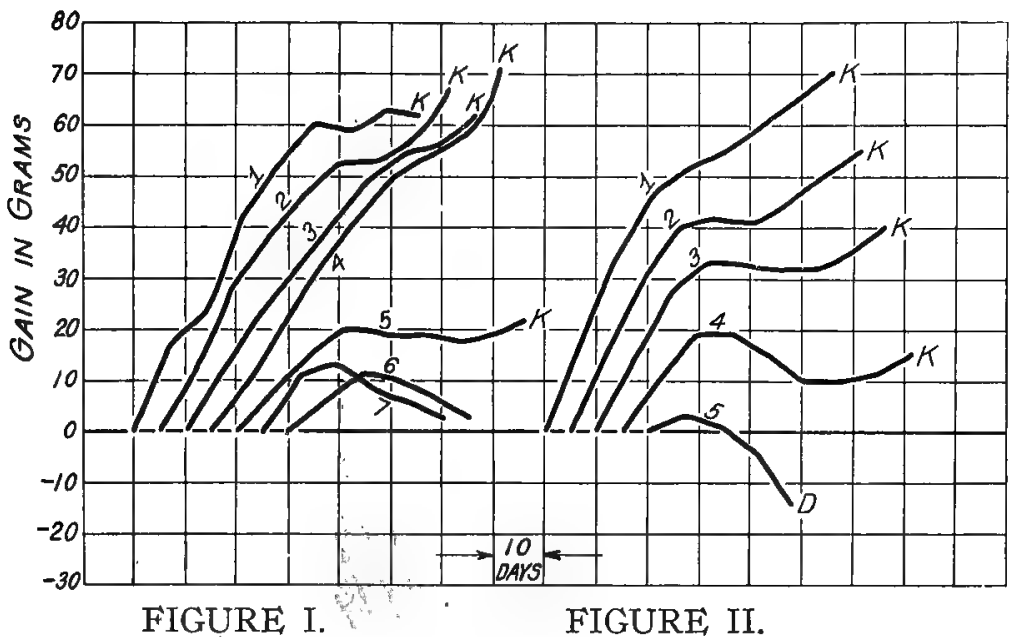

Figure I.

Average gain curves of rats on diet 94 plus various amounts of skimmed milk.

Curve 1 Diet $94+15$ cc. milk

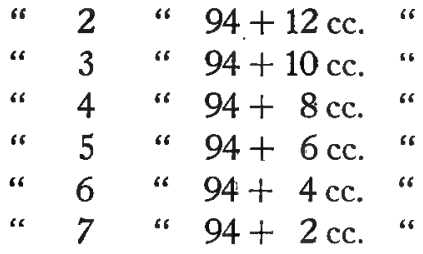

Figure II.

Average gain curves of rats on diet 107 plus various amounts of skimmed milk.

Curve 1 Diet $107+12$ cc. milk

$\begin{array}{lllll} & 2 & \text { " } & 107+10 \mathrm{cc} . & \text { " } \\ & 3 & \text { " } & 107+8 \mathrm{cc} \text {. } & \text { " } \\ & 4 & \text { " } & 107+6 \mathrm{cc} \text {. } & \\ & 5 & \text { " } & 107 \text { no milk } & \end{array}$

$\mathrm{K} .=$ killed. $\quad \mathrm{D} .=$ died.

The last point on the curve is the average age and weight at death. Curves 6 and 7 in Figure I could not be completed as some of the rats died before the end of the experimental period of eight weeks. 
CHART II.

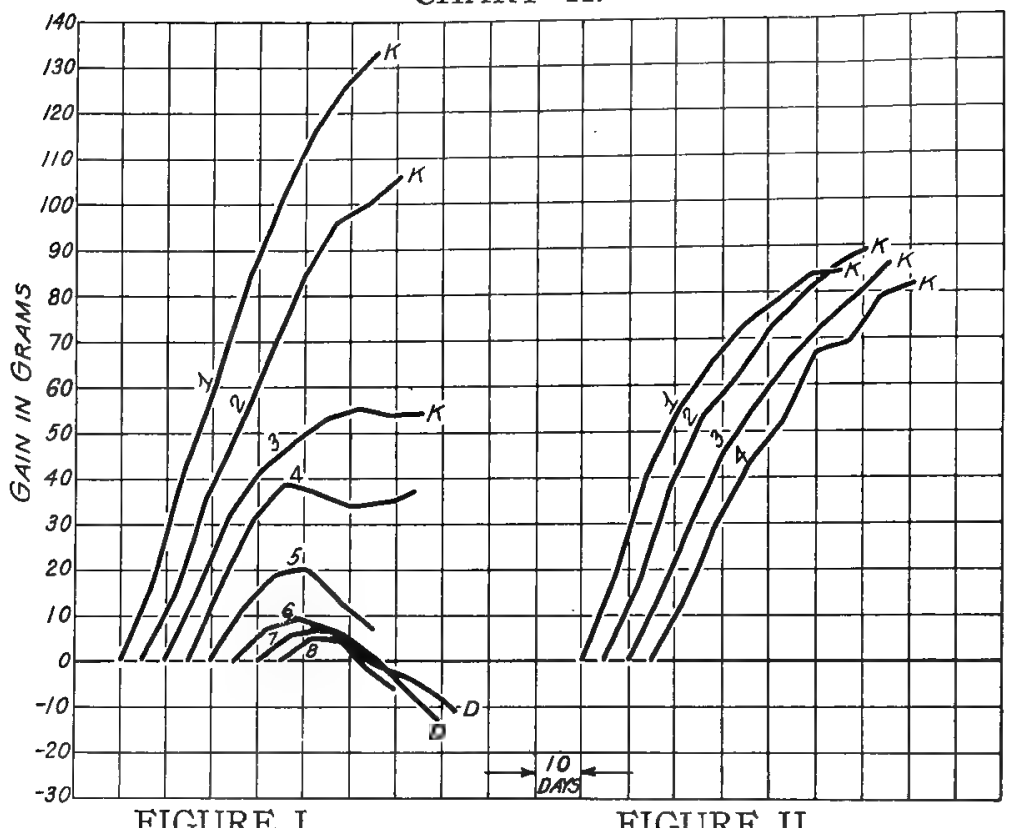

Figure I.

Curve 1 Average gain curve of rats on diet 101 (30\% milk)

$$
\begin{aligned}
& \text { " } 2 \text { " } 3 \text { " " " " " " " " } 3100 \text { ( } 35 \% \text { milk) } \\
& \text { " } 3 \text { " “ " " " " " " " } 99 \text { " } 20 \% \text { milk } \\
& \text { " } 4 \text { " " " " " " " " " } \\
& \text { " } 5 \text { " " " " " " " " " } " 96 \text { (10\% milk) } \\
& \text { "6 " " " " " " " " " } 697 \text { " } 5 \% \text { milk) }
\end{aligned}
$$

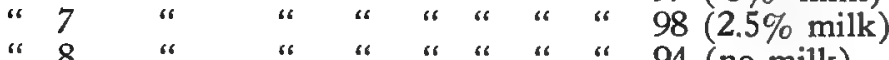

$$
\begin{aligned}
& \text { " } 8 \text { " " " " " " } 94 \text { (no milk) }
\end{aligned}
$$

Figure II.

Curve 1 Average gain curve of rats on diet 100 (milk unheated)

$$
\begin{aligned}
& \text { " } 2 \text { " " " " " } 100 \text { (milk heated } \\
& \text { " } 3 \text { " " " " " " } " 100 \text { (milk heated } \\
& 24 \text { hrs. at } 100^{\circ} \mathrm{C} \text {.) } \\
& \text { " } 4 \text { " " " " " } 100 \text { (milk heated } \\
& \text { D. = died. } \\
& 48 \text { hrs. at } 100^{\circ} \mathrm{C} \text {.) }
\end{aligned}
$$

$\mathrm{K} .=$ killed.

The last point on the curve is the average age and weight at death. Curves 4,5 and 6 in Figure I could not be completed as some of the rats died before the end of the experimental period of eight weeks. 


\section{BIBLIOGRAPHY}

${ }^{1}$ Hopkins: The analyst and the medical man. Analyst 1906 XXXI 385.

'Hopkins: Feeding experiments illustrating the importance of accessory factors in normal dietaries. Jour. Physiol. 1912 XLIV 425.

${ }^{8}$ Osborne and Mendel: Feeding experiments with isolated food substances. Carnegie Inst. of Washington 1911 Pub. No. 156.

1 Osborne and Mendel: The relation of growth to the chemical constituents of the diet. Jour. Biol. Chem. 1913 XV 311.

${ }^{5}$ Osborne and Mendel: The role of vitamines in the diet. Jour. Biol. Chem. 1917 XXXI 149.

${ }^{\circ}$ Osborne and Mendel: Nutritive factors in plant tissues. II. The distribution of water-soluble vitamine. Jour. Biol. Chem. 1919 XXXIX 29.

"Osborne and Mendel: Nutritive factors in plant tissues. III. Further observations on the distribution of watersoluble vitamine. Jour. Biol. Chem. 1920 XLI 451.

${ }^{*}$ McCollum: The newer knowledge of nutrition 1922.

${ }^{9}$ McCollum and Davis: Essential factors in the diet during growth. Jour. Biol. Chem. 1915 XXIII 231.

${ }^{10}$ McCollum and Davis: Nutrition with purified food substances. Jour. Biol. Chem. 1915 XX 641.

${ }^{11}$ McCollum and Davis: The nature of the dietary deficiencies of rice. Jour. Biol. Chem. 1915 XXIII 181.

${ }^{12}$ Eijkman: An illness of fowls similar to beriberi. Virchow's Arch. 1897 CXLVIII 823.

${ }^{13}$ E,ijkman: Nutritional polyneuritis. Arch. Hyg. 1906 LVIII 150.

${ }^{14}$ Eijkman: Polyneuritis gallinarum and beriberi. Arch. Schiffs-Tropen Hyg. 1911 XV 698.

15 Funk: The vitamines. Trans. by Dubin 1922.

${ }^{15}$ Funk: Chemical nature of the substance which cures polyneuritis in birds induced by a diet of polished rice. Jour. Physiol. 1911 XLIII 395, 1912 XLV 75. 
17 Williams: Chemical nature of the vitamines. I. Antineuritic properties of the hydroxypyridines. Jour. Biol. Chem. 1916 XXV 437.

${ }^{18}$ Williams : Chemical nature of the vitamines. III. The structure of the curative modifications of the hydroxypyridines. Jour. Biol. Chem. 1917 XXIX 495.

${ }^{19}$ Williams: Chemistry of the vitamines. Philippine Jour. Sci. 1916 Ser. A XI 49.

${ }^{20}$ Williams and Seide1l: The chemical nature of the vitamines III. Isomerism in natural antineuritic substances. Jour. Biol. Chem. XXVI 431.

${ }^{21}$ Wildier: La Cellule 1901 XVIII 313.

${ }^{22}$ Sherman and Smith: The vitamins. 1922.

23. Williams: The vitamine requirements of yeast. A simple biological test for vitamine. Jour. Biol. Chem. 1919 XXXVIII 495.

${ }^{24}$ Williams : A quantitative method for the determination of vitamine. Jour. Biol. Chem. 1920 XLII 259.

${ }^{25}$ Williams: Vitamine and yeast growth. Jour. Biol. Chem. 1921 XLVI 113.

${ }^{26}$ Bachman: Vitamine requirements of certain yeasts. Jour. Biol. Chem. 1919 XXXIX 235.

${ }^{27}$ Eddy and Stevenson: The suitability of the Bachman test for water-soluble B. Proc. Soc. Exp. Biol. Med. 1919 XVII 52.

${ }^{28}$ Eddy and Stevenson: Studies in the vitamine content. Jour. Biol. Chem. 1920 XLIII 295.

${ }^{29}$ Emmett and Stockholm: Water-soluble vitamines. II. The relation of the antineuritic and water-soluble $B$ vitamines to the yeast growth promoting stimulus. Jour. Biol. Chem. 1920 XLIII 287.

${ }^{30}$ Fulmer, Nelson and Sherwood: The nutritive requirement of yeast. Jour. Amer. Chem. Soc. 1921 XLIII 191.

${ }^{31}$ Funk and Dubin: A test for antiberiberi vitamine and its practical application. Jour. Biol. Chem. 1920 XLIV 487.

${ }^{82}$ McDonald and McCollum : The cultivation of yeast in solutions of purified nutrients. Jour. Biol. Chem. 1921 XLV 307. 
${ }^{33}$ McDonald and McCollum: The bios of Wildiers and the cultivation of yeast. Jour. Biol. Chem. 1921 XLVI 525. 3.t Nelson, Fulmer and Cessna: The nutritional requirements of yeast. III. The synthesis of water-soluble B by yeast. Jour. Biol. Chem. 1921 XLVI 77.

${ }^{35}$ Souza and McCollum: A study of the factors which interfere with the use of yeast as a test organism for the antineuritic substance. Jour. Biol. Chem. 1920 XLIV. 113. ${ }^{36}$ Hopkins, Chick et al: Report on the present state of knowledge concerning accessory food factors (vitamines). Medical Research Committee Special Report No. 38 1919.

${ }^{37}$ Edgeworth: Experiments with two methods for the study of vitamin B. Dissertation 1922.

${ }^{38}$ McCarrison: Studies in deficiency diseases. Oxford University Press. 1921.

${ }^{39}$ Osborne, Wakeman and Ferry: Preparation of protein free from water soluble vitamine. Jour. Biol. Chem. 1919 XXXIX 35.

4n Osborne and Mendel: Nutritive value of the wheat kernel. Jour. Biol. Chem. 1919 XXXVII 572.

${ }^{41}$ Kennedy and Dutcher: Vitamine studies. IX. The influence of the diet of the cow upon the quality of the vitamines $A$ and B in milk. Jour. Biol. Chem. 1922 L, 339.

${ }^{42}$ Hopkins: Note on the vitamine content of milk. Biochem. Jour. 1920 XIV 721.

${ }^{43}$ Osborne and Mendel: Milk as a source of water-soluble vitamine. Jour. Biol. Chem. 1918 XXXIV 537.

${ }^{44}$ Osborne and Mendel: Milk as a source of water-soluble vitamine. II. Jour. Biol. Chem. 1920 XLI 515. 


\section{I T A}

Adelaide Spohn was born in Chicago, Illinois, May 25, 1886. In 1908 she received the degree of B. S. from the University of Chicago and in 1913 the degree of M. S. from the same University. Since 1908 she has held the following positions: Instructor, Woodstock, Illinois, High School 19081910 ; Instructor, Joliet, Illinois, Township High School 1910. 1911 ; Research Assistant to Dr. Oscar Riddle at the University of Chicago and Station of Experimental Evolution of the Carnegie Institution of Washington, 1911-1915; Instructor in Chemistry, Teachers College, 1915-1916; Chemical Assistant in the Department of Physiology, Columbia University, 1916 to February, 1918; Instructor in Chemistry Northwestern University, February 1918-1919; Instructor in Chemistry, Pratt Institute, 1919-1920; Research Assistant in Food Chemistry, Columbia University, 1920-1922.

She was co-author with Dr. Oscar Riddle of the following publications: Studies on the Physiology of Reproduction in Birds. II. On the Chemical Composition of White and Yellow Egg Yolk of the Fowl and Pigeon, Am. Jour. Physiol, 1916, XLI, 397 ; Studies on the Physiology of Reproduction in Birds. IV. When a Gland Functions for the First Time is its Secretion the Equivalent of Subsequent Secretions? Am. Jour. Physiol. 1916, XLI, 419.

She has been a graduate student under the Faculty of Pure Science, Columbia University, during the years 1915-16 and $1920-22$. 

Lansing-Broas Print

231 Union St.

Poughkeepsie, N. Y. 

incosing

axis

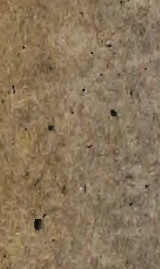

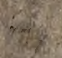
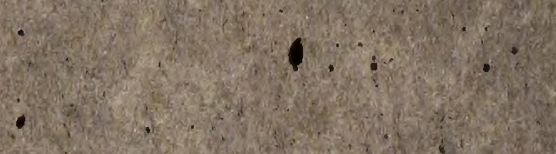

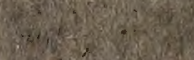

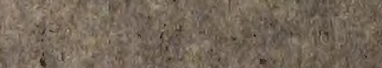
9.

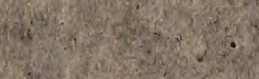
4. is

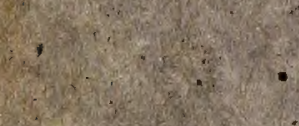

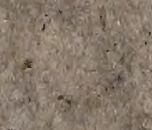

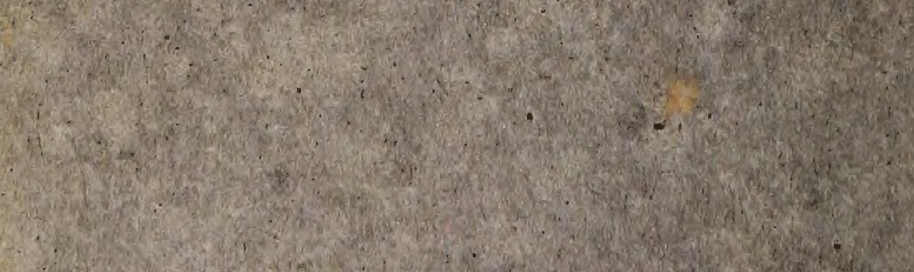

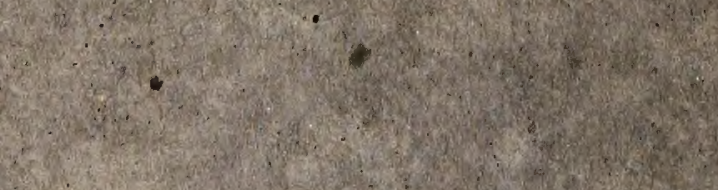

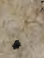

a.
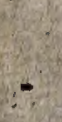